\title{
Introducing a special edition of the Journal of Muscle Research and Cell Motility on tropomyosin: form and function
}

\author{
Steven Marston • Matthias Gautel
}

Received: 17 September 2013/Accepted: 19 September 2013/Published online: 8 October 2013

(C) Springer Science+Business Media Dordrecht 2013

The Journal of Muscle Research and Cell Motility aims to serve its readers both by publishing original research on muscle and motility and by informing readers of the state of the art in muscle and cell motility research and to promote discussions.

With this aim in mind, we present the second of our occasional series of topical special issues that combine original research with review articles related to an individual protein important for muscle and motility. The first special edition was devoted to Myosin Binding Protein-C (May 2012), and this edition is devoted to tropomyosin.

In the last year, we have also published special issues on Lifestyle and Ageing in Muscle Disease (August 2012) and A Tribute to the Life and Science of Michael and Kate Bárány (December 2012). Further topical issues are planned, and we would welcome ideas for themes to be covered in the future.

Tropomyosin was first isolated from striated muscles by Bailey (1948). For many years, it was regarded as an archetypal coiled-coil protein with no known function, mainly of interest to X-ray "diffractionists", and it was several decades before its location in the muscle sarcomere and its function were discovered. The key findings were the determination that tropomyosin was a component of the muscle thin filament, based on the electron microscopy and X-ray studies of Huxley, Hanson and Lowy (Hanson and Lowy 1963; Moore et al. 1970), and the discovery that tropomyosin was a component of the $\mathrm{Ca}^{2+}$ dependent regulatory complex of striated muscle (Ebashi 1963).

By 1972, when the celebrated Cold Spring Harbour Symposium on muscle was published, tropomyosin had

S. Marston $(\bowtie) \cdot$ M. Gautel

London, UK

e-mail: s.marston@imperial.ac.uk come of age. Tropomyosin, in concert with troponin, was shown to regulate the activity of the thin filament in response to $\mathrm{Ca}^{2+}$ (Ebashi and Endo 1968), to confer cooperativity to thin filament regulation (Bremel et al. 1972; Bremel and Weber 1972). It was discovered that tropomyosin formed a continuous strand that was wound round the actin helix and changed its position in response to $\mathrm{Ca}^{2+}$ or myosin head binding, and as a result, the steric blocking hypothesis of regulation was born (Huxley 1972; Moore et al. 1970; Parry and Squire 1973). Skeletal tropomyosin was sequenced (Hodges et al. 1972; Sodek et al. 1972) and the sites of interaction with actin were mapped out (McLachlan et al. 1975).

The molecular biology revolution of the 1980s revealed that although tropomyosin is one of the most highly conserved proteins and is present in all eukaryocytes, it is extremely diverse: in vertebrates there are 4 tropomyosin genes (TPM 1-4) and each gene can generate many tissuespecific isoforms by alternative splicing of exons (Vrhovski et al. 2008). Indeed, tropomyosin has been a favoured model for studying the mechanisms of exon splicing (Gooding et al. 1994; Gooding and Smith 2008). The study of the function of tropomyosin outside of the muscle sarcomere has also become important (Lin et al. 1985) especially in the context of altered actomyosin cell motility in cancer cells (Choi et al. 2012; Franzén et al. 1996; Helfman et al. 2008; Stehn et al. 2013), and extrapolation of these results suggests that the development of compounds directed against specific classes of malfunctional tropomyosins could also be possible in striated muscle.

An admirable review of tropomyosin by Sam Perry was published in the Journal of Muscle Research in 2001 (Perry 2001), and the articles in this issue bring tropomyosin studies fully up to date. The structure of tropomyosin and 
its formation into dimers is described by Janco et al. (2013) and the structure of tropomyosin incorporated into the thin filament is described by Lehman et al. (2013). The article by Colpan et al. (2013) describes the end-capping of thin filaments by tropomodulin. Reconciliation of functional studies on tropomyosin's role in muscle regulation with the structural models, as represented by the steric blocking hypothesis has been controversial since the seminal study of Chalovich et al. (1981): a forthcoming article by ElMezgueldi will describe the dynamics of tropomyosin and how they contribute to its role in thin filament regulation.

Tropomyosin has been considered to be a phosphorylated protein for many years, but until recently, these studies have not attracted much interest: the history of tropomyosin phosphorylation in striated muscles is described by Heeley (2013) and the possibilities of phosphorylation playing a modulatory role in cardiac muscle is described by Schulz and Wieczorek (2013). Three papers tackle the question of what is the level of tropomyosin phosphorylation and the isoforms expressed in human heart and in eye muscles (Marston et al. 2013; Peng et al. 2013; Bicer and Reiser 2013).

In recent years, mutations in skeletal muscle tropomyosin have been identified as causative of some forms of congenital skeletal myopathy, and mutations in alpha tropomyosin have been found as a rare cause of both hypertrophic cardiomyopathy and dilated cardiomyopathy. The articles by Memo and Marston (2013) and by Ochala and Iwamoto (2013) consider the molecular mechanisms by which skeletal muscle mutations cause myopathy. Redwood and Robinson review current understanding of tropomyosin mutations causing cardiomyopathies, and Kawai et al. (Bai et al. 2013) present functional studies on the effect of tropomyosin mutations in reconstituted cardiac muscle fibres.

Finally, the roles of tropomyosin outside the sarcomere are discussed. Vindin and Gunning (2013) make the case for cytoskeletal tropomyosins as choreographers of actin filament functional diversity, whilst Chase et al. (2013) describe the possible roles of tropomyosin in the nucleus.

In summary, the tropomyosin molecule, as a predominantly coiled-coil parallel dimer with 284 amino acids (245 in non-muscle systems), is deceptively simple. It interacts only with itself, by end-to-end linkages, and with actin, troponin $\mathrm{T}$ and tropomodulin- yet, its cooperative and allosteric interactions are vital in muscle regulation and have now been found to play a role in many other cellular processes. There is much that can be learned from studying tropomyosin. Its multiplicity of isoforms exquisitely tune the structure and function to the requirements of different tissues in ways that are not yet understood. On the other hand, advances in structural, functional and genetic studies are approaching the point where a complete description of the role of tropomyosin in the muscle thin filament may be achieved and point to the possibility of sarcomeric proteins as viable drug targets.

\section{References}

Bai F, Wang L, Kawai M (2013) A study of tropomyosin's role in cardiac function and disease using thin-filament reconstituted myocardium. J Muscle Res Cell Motil 34. doi:10.1007/s10974013-9343-z

Bailey K (1948) Tropomyosin: a new asymmetric protein component of the muscle fibril. Biochem J 43:271-273

Bicer S, Reiser P (2013) Complex tropomyosin and troponin T isoform expression patterns in orbital and global fibers of adult dog and rat extraocular muscles. J Muscle Res Cell Motil 34. doi:10.1007/s10974-013-9346-9

Bremel RD, Weber A (1972) Cooperation within actin filament in vertebrate skeletal muscle. Nat New Biol 238:97-101

Bremel RD, Murray JM, Weber A (1972) Manifestations of cooperative behaviour in the regulated actin filament during actin-activated ATP hydrolysis in the presence of calcium. Cold Spring Harb Symp Quant Biol 37:267-275

Chalovich JM, Chock PB, Eisenberg E (1981) Mechanism of action of troponin.tropomyosin. Inhibition of actomyosin ATPase activity without inhibition of myosin binding to actin. J Biol Chem 256:575-578

Chase PB, Szczypinski M, Soto E (2013) Nuclear tropomyosin and troponin in striated muscle: new roles in a new locale? J Muscle Res Cell Motil 34. doi:10.1007/s10974-013-9356-7

Choi C, Kim D, Kim S, Jeong S, Song E, Helfman DM (2012) From skeletal muscle to cancer: insights learned elucidating the function of tropomyosin. J Struct Biol 177:63-69

Colpan M, Moroz N, Kostyukova A (2013) Tropomodulins and tropomyosins: working as a team. J Muscle Res Cell Motil 34. doi:10.1007/s10974-013-9349-6

Ebashi S (1963) Third component participating in the superprecipitation of "Natural Actomyosin". Nature 200:1010

Ebashi S, Endo M (1968) Calcium ion and muscle contraction. Prog Biophys Mol Biol 18:125-183

Franzén B, Linder S, Uryu K, Alaiya AA, Hirano T, Kato H, Auer G (1996) Expression of tropomyosin isoforms in benign and malignant human breast lesions. Br J Cancer 73:909-913

Gooding C, Smith CWJ (2008) Tropomyosin exons as models for alternative splicing. Adv Exp Med Biol 644:27-42

Gooding C, Roberts GC, Moreau G, Nadal-Ginard B, Smith CWJ (1994) Smooth muscle-specific switching of $\alpha$-tropomyosin mutually exclusive exon selection by specific inhibition of the strong default exon. EMBO J 13:3861-3872

Hanson J, Lowy J (1963) The structure of F-actin and actin filaments isolated from muscle. J Mol Biol 6:46-60

Heeley D (2013) Phosphorylation of tropomyosin in striated muscle. J Muscle Res Cell Motil 34. doi:10.1007/s10974-013-9351-z

Helfman DM, Flynn P, Khan P, Saeed A (2008) Tropomyosin as a regulator of cancer cell transformation. Adv Exp Med Biol 644:124-131

Hodges RS, Sodek J, Smillie LB, Jurasek L (1972) Tropomyosin: amino acid sequence and coiled-coil structure. Cold Spring Harb Symp Quant Biol 37:299-310

Huxley HE (1972) Structural changes in actin- and myosincontaining filaments during contraction. Cold Spring Harb Symp Quant Biol 37:225-234

Janco M, Suphamungmee W, Li X, Lehman W, Lehrer S, Geeves M (2013) Polymorphism in tropomyosin structure and function. J Muscle Res Cell Motil 34. doi:10.1007/s10974-013-9353-x 
Lehman W, Orzechowski M, Li X, Fischer S, Raunser S (2013) Gestalt-binding of tropomyosin on actin during thin filament activation. J Muscle Res Cell Motil 34. doi:10.1007/s10974-0139342-0

Lin JJ, Helfman DM, Hughes SH, Chou CS (1985) Tropomyosin isoforms in chicken embryo fibroblasts: purification, characterization, and changes in Rous sarcoma virus-transformed cells. J Cell Biol 100:692-703

Marston S, Copeland ON, Messer A, MacNamara E, Nowak K, Zampronio C, Ward D (2013) Tropomyosin isoform expression and phosphorylation in the human heart in health and disease. J Muscle Res Cell Motil 34. doi:10.1007/s10974-013-9347-8

McLachlan AD, Stewart M, Smillie LB (1975) Sequence repeats in alpha-tropomyosin. J Mol Biol 98:281-291

Memo M, Marston S (2013) Skeletal muscle myopathy mutations at the actin tropomyosin interface that cause gain- or loss-offunction. J Muscle Res Cell Motil 34. doi:10.1007/s10974-0139344-y

Moore PB, Huxley HE, DeRosier DJ (1970) Three-dimensional reconstruction of F-actin, thin filaments and decorated thin filaments. J Mol Biol 50:279-295

Ochala J, Iwamoto H (2013) Myofilament lattice structure in presence of a skeletal myopathy-related tropomyosin mutation. J Muscle Res Cell Motil 34. doi:10.1007/s10974-013-9345-x

Parry DAD, Squire JM (1973) Structural role of tropomyosin in muscle regulation: analysis of the X-ray patterns from relaxed and contracting muscles. J Mol Biol 75:33-55
Peng Y, Yu D, Gregorich Z, Chen X, Beyer A, Gutterman D, Ge Y (2013) In-depth proteomic analysis of human tropomyosin by top-down mass spectrometry. J Muscle Res Cell Motil 34. doi:10.1007/s10974-013-9352-y

Perry SV (2001) Vertebrate tropomyosin: distribution, properties and function. J Musc Res Cell Motil 22:5-49

Redwood C, Robinson P (2013) Alpha-tropomyosin mutations in inherited cardiomyopathies. J Muscle Res Cell Motil 34. doi:10. 1007/s10974-013-9358-5

Schulz E, Wieczorek D (2013) Tropomyosin de-phosphorylation in the heart: what are the consequences? J Muscle Res Cell Motil 34. doi:10.1007/s10974-013-9348-7

Sodek J, Hodges RS, Smillie LB, Jurasek L (1972) Amino-acid sequence of rabbit skeletal tropomyosin and its coiled-coil structure. Proc Natl Acad Sci USA 69:3800-3804

Stehn JR, Haass NK, Bonello T, Desouza M, Kottyan G, Treutlein H, Zeng J, Nascimento PRBB, Sequeira VB, Butler TL, Allanson M, Fath T, Hill TA, McCluskey A, Schevzov G, Palmer SJ, Hardeman EC, Winlaw D, Reeve VE, Dixon I, Weninger W, Cripe TP, Gunning PW (2013) A novel class of anticancer compounds targets the actin cytoskeleton in tumor cells. Cancer Res 73:5169-5182

Vindin H, Gunning P (2013) Cytoskeletal tropomyosins: choreographers of actin filament functional diversity. J Muscle Res Cell Motil 34. doi:10.1007/s10974-013-9355-8

Vrhovski B, Thézé N, Thiébaud P (2008) Structure and evolution of tropomyosin genes. Adv Exp Med Biol 644:6-26 